\title{
Mosaic structure of large regions of the Lactococcus lactis subsp. cremoris chromosome
}

\author{
C. Delorme, J.-J. Godon, S. D. Ehrlich and P. Renault
}

Author for correspondence: P. Renault. Tel: +331346525 25. Fax: + 331346525 21. e-mail: renault@biotec.jouy.inra.fr

Laboratoire de Génétique Microbienne, Institut National de la Recherche Agronomique, 78352 Jouyen-Josas Cedex, France

\begin{abstract}
Lactococcus lactis subsp. lactis and Lactococcus lactis subsp. cremoris are closely related phenotypically and genetically. Here we report that certain regions of their chromosomes diverge considerably more than others. Conserved regions differ by less than $20 \%$, whilst variable regions differ by more than $60 \%$. This mosaic structure may have arisen by horizontal gene transfer from distantly related bacteria since in a particular region of the $L$. lactis subsp. cremoris chromosome the $\mathbf{G}+\mathbf{C}$ content and the codon bias are not typical for lactococci. Such an exchange, which conserves the function of the gene and cannot be achieved under selective pressure, may be of considerable importance in the evolution of bacteria.
\end{abstract}

Keywords: Lactococcus lactis subsp. lactis, Lactococcus lactis subsp. cremoris, horizontal gene transfer, chromosome structure

\section{INTRODUCTION}

The genus Lactococcus is a distinct and homogeneous group of lactic acid bacteria (Collins et al., 1989) isolated from dairy products, plants, and the mucosa and digestive tract of animals. Within the genus, the status of Lactococcus lactis subsp. lactis (Streptococcus lactis Lister 1873) and Lactococcus lactis subsp. cremoris (Streptococcus cremoris OrlaJensen 1919) as separate species or subspecies has been the subject of some debate, since their phenotypic differentiation is difficult. Garvie \& Farrow (1982) proposed that both organisms belong to a single species because of similarities in their phenotype and DNA homology, which was reported to be $80 \%$ for the type strains and to range between 75 and 100\% (Jarvis et al., 1981). This classification is supported by the high degree of homology of $L$. lactis subsp. lactis and L. lactis subsp. cremoris $16 \mathrm{~S}$ rRNA (Collins et al., 1989; Salama et al., 1991). However, it has been argued that $16 \mathrm{~S}$ rRNA sequence identity may not be sufficient to guarantee species identity (Fox et al., 1992) and the lactis/cremoris classification was questioned by the recent evidence that certain genes of one subspecies hybridize only very weakly with those of the other (Godon et al., 1992b).

To extend the previous observations we undertook

\footnotetext{
Abbreviation: BCAA, branched-chain amino acid.
}

The GenBank accession number for the nucleotide sequence reported in this paper is L $\mathrm{L} 35562$. hybridization analysis of the entire tryptophan, histidine and branched-chain amino acid (BCAA; isoleucine, leucine and valine) operons. Interestingly, a mosaic structure of the operons was found, with alternating conserved and divergent regions.

\section{METHODS}

Bacterial strains, plasmids, phage and media. The bacterial strains, plasmids and the phage used in this work were described previously (Delorme et al., 1992; Godon et al., 1992a). Strains earlier misclassified as $L$. lactis subsp. lactis are here termed $L$. lactis subsp. cremoris as proposed previously (Godon et al., 1992b). Lactococcal strains were grown in M17 medium (Terzaghi \& Sandine, 1975).

Cloning of L. lactis subsp. cremoris NCDO 763 DNA in Escherichia coli. Total DNA from lactococci was isolated by standard procedures (Loureiro Dos Santos \& Chopin, 1987). Subcloning of total DNA was carried out in pBluescript plasmid (Stratagene). A ligation mix was used to transform competent E. coli cells, as described by Sambrook et al. (1989). To isolate the $2.5 \mathrm{~kb}$ segment, previously detected in $L$. lactis subsp. cremoris DNA by hybridization with the bis operon of L. lactis subsp. lactis (Godon et al., 1992b), a partial L. lactis subsp. cremoris genomic library was prepared. EcoRI DNA fragments ranging from 2.2 to $2.7 \mathrm{~kb}$ were purified by gel electrophoresis and ligated to a dephosphorylated $\mathrm{pBluescript}$ vector. The relevant clones were identified by colony hybridization at low stringency (25\%, v/v, formamide) with pIL704 (Delorme et al., 1992) as probe. Three positive clones harboured the same plasmid, as judged by its size and by restriction analysis. One, designated pIL732, was chosen for further study. 

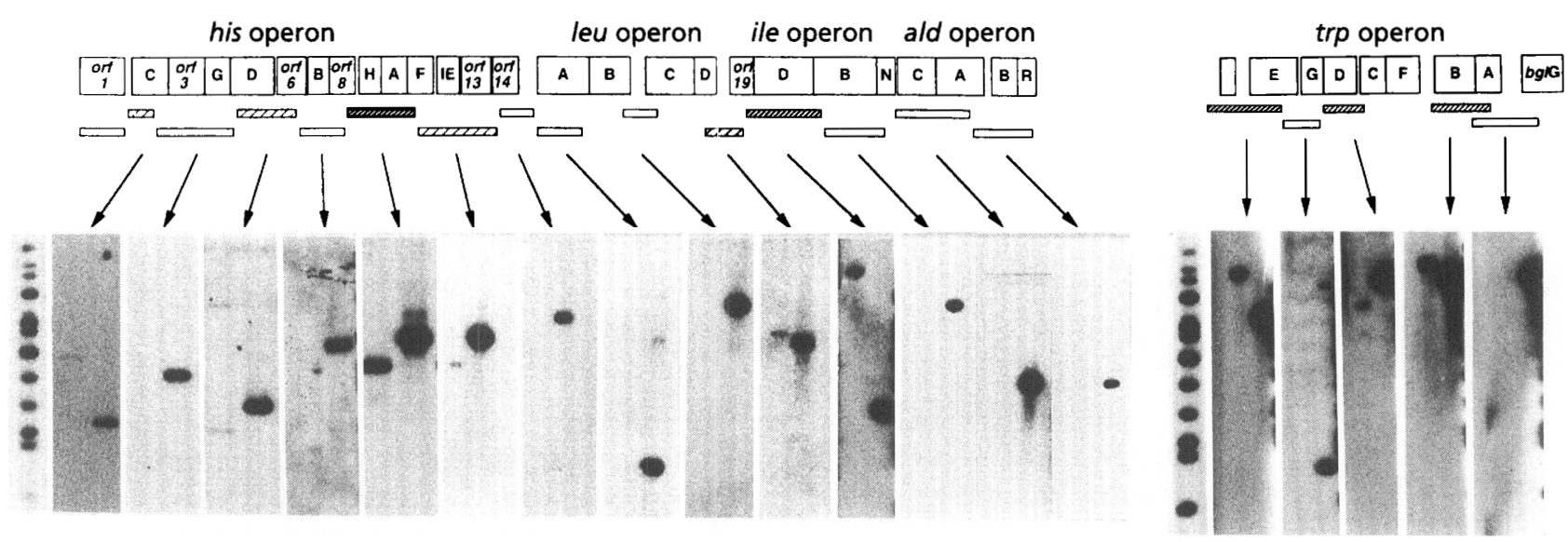

Fig. 1. Organization of the $30 \mathrm{~kb} \mathrm{~L}$. lactis subsp. lactis chromosomal region covering the histidine and the BCAA operons and the $8 \mathrm{~kb}$ region covering the tryptophan operon. Top: genetic organization. Middle: the L. lactis subsp. lactis probes used for the Southern experiments. The heavy and light hatched boxes denote a strong and weak hybridization signal, respectively, at high stringency. The white boxes denote the absence of a signal. Bottom: results of the hybridization experiments at high stringency. L. lactis subsp. cremoris and L. lactis subsp. lactis DNA are in left and right lanes, respectively, in each experiment. Raoul size markers are shown in the leftmost lane $(15 \cdot 0,9 \cdot 0,7 \cdot 3,5 \cdot 6,4 \cdot 3,4 \cdot 0,3 \cdot 6,2 \cdot 9,2 \cdot 3$, $1 \cdot 8,1 \cdot 4,1 \cdot 2,0.75 \mathrm{~kb})$.

A $1.5 \mathrm{~kb}$ chromosomal fragment of the L. lactis subsp. cremoris bis operon was amplified by the polymerase chain reaction (PCR) using the primers His1 (CCAATATCAACAATTCCATG, nucleotides 1809-1790 of NCDO 763) and His2 (ATTTCTGATTGGTTACGGAT, nucleotides 329-348). The amplified fragment was either rendered blunt-ended with T4 polymerase and inserted into pBluescript in the EcoR. $V$ site or partially cut with $A l u \mathrm{I}$ and cloned in the M13mp18 vector cleaved with $S m a I$.

Southern hybridization analysis. Standard procedures were used (Sambrook et al., 1989) with $2 \mu \mathrm{g}$ of chromosomal DNA. DNA segments were transferred to a nylon membrane (Pal Biodyne) and hybridized with probes that were labelled with $\left[{ }^{32} \mathrm{P}\right] \mathrm{dCTP}$ by the random priming procedure (Boehringer). Stringency of hybridization was controlled by varying the formamide concentration as previously described (Godon $\mathrm{et} \mathrm{al \text {, }}$ 1992). The filters were washed twice in $2 \times \mathrm{SSC}$ at $42^{\circ} \mathrm{C}$ and then twice at $50^{\circ} \mathrm{C}$.

DNA sequence analysis. Nested deletions were produced by the action of DNase I on pBluescript plasmids containing the segments to be sequenced. Single-stranded DNA was prepared as described by Vieira \& Messing (1987) and sequenced essentially according to the Applied Biosystems protocol accompanying the $370 \mathrm{~A}$ DNA sequencer. The DNA was used in dideoxynucleotide chain-termination sequencing reactions with Taq DNA polymerase and fluorescent dye-coupled primers (Applied Biosystems). The reported sequence was determined on both DNA strands. Errors arising from gene amplification were resolved by sequencing at least two independently cloned segments.

The DNA and protein sequences were analysed using the BISANCE and the University of Wisconsin GCG packages, implemented at the Centre InterUniversitaire d'Informatique à Orientation Biomédicale, Paris.

\section{RESULTS}

\section{Heterogeneity of the L. lactis subsp. cremoris chromosome}

In a previous study, certain $L$. lactis subsp. lactis DNA segments were found to hybridize only very weakly with the chromosomal DNA of L. lactis subsp. cremoris (Godon et al., 1992b). To determine whether the level of divergence between $L$. lactis subsp. lactis and $L$. lactis subsp. cremoris DNA varies significantly along the chromosome we undertook the following Southern hybridization analysis. Segments of two previously sequenced $L$. lactis subsp. lactis chromosomal regions of $\sim 30$ and $\sim 8 \mathrm{~kb}$, covering a total of $1.6 \%$ of the chromosome and containing his (Delorme et al., 1992), leu-ilv-ald (Godon et al., 1992a) and trp (Bardowski et al., 1992) operons (Fig. 1 ), were hybridized with $L$. lactis subsp. cremoris DNA at a stringency low enough to detect homology of $>80 \%$. Hybridization was observed with some, but not all, probes (Fig. 1). Control experiments indicated that all probes hybridized with $L$. lactis subsp. cremoris DNA at a lower stringency ( $25 \%$ formamide, data not shown). We conclude that $L$. lactis subsp. lactis and L. lactis subsp. cremoris diverge considerably in certain chromosomal regions and less in others.

\section{Sequence of a DNA segment from the $L$. lactis subsp. cremoris his operon}

To determine more precisely the level of divergence between the poorly hybridizing segments, the sequence of the $2.5 \mathrm{~kb}$ segment from the $L$. lactis subsp. cremoris bis operon, carried on pIL732 (third box in Fig. 1, see Methods), was determined and compared with the sequence of the corresponding segment of $L$. lactis subsp. 
lactis NCDO 2118 (Fig. 2). The sequence of this fragment was previously compared in two $L$. lactis subsp. lactis strains and was found to be more than $98 \%$ identical (Delorme et al., 1993). The L. lactis subsp. cremoris sequence is $\sim 200 \mathrm{bp}$ longer, due to an insertion extending from position 1384 to 1597 . Excluding the insertion, alignment of the two sequences is possible, the mean divergence being $\sim 27 \%$. Surprisingly, divergence is much greater in certain regions than in others, as seen by comparing $70 \mathrm{bp}$ intervals of the two sequences (Fig. 3 ). It is relatively high, up to $65 \%$ with a mean of $\sim 45 \%$, in the central region (positions 480-1700), with only one better conserved interval (15\% divergence, see below for possible explanation). In contrast, divergence is relatively low, $10-30 \%$ with a mean of $\sim 15 \%$, at the $3^{\prime}$ end (beyond position 1750). Some short divergent stretches are interspersed at the conserved $5^{\prime}$ end (up to position 480). Interestingly, the $G+C$ content of the entire divergent central region of the $L$. lactis subsp. cremoris segment is quite high, $48 \mathrm{~mol} \%$, whereas that of the corresponding region of $L$. lactis subsp. lactis is only $36 \mathrm{~mol} \% \mathrm{G}+\mathrm{C}$, which is close to the $38 \mathrm{~mol} \%$ found for total L. lactis DNA (Garvie \& Farrow, 1982). In contrast, the $\mathrm{G}+\mathrm{C}$ content of both $5^{\prime}$ and $3^{\prime}$ conserved regions is not significantly different.

The insertion present in the highly divergent central region of the $L$. lactis subsp. cremoris bis segment is composed of (i) three quasi-perfect repeats of $59 \mathrm{bp}$ (position 1400-1582) and (ii) two flanking non-repeated and non-coding stretches, of 22 and $28 \mathrm{bp}$, respectively (Fig. 2). A remarkable feature of this insertion is its high $\mathrm{G}+\mathrm{C}$ content (54 mol\%), which is higher than that of the flanking region $(48 \mathrm{~mol} \%)$.

\section{Analysis of the coding sequences}

Variations in the extent of divergence found in the bis operon could be due to rapid accumulation of mutations or to acquisition of DNA from phylogenetically distant species by horizontal gene exchange. In the first case, the divergent regions would almost certainly conserve codon usage (assuming that the gene was functional after it diverged) whilst in the second the chances are that the codon usage would be different. These considerations led us to compare the coding properties of the previously sequenced $L$. lactis subsp. lactis and cremoris segments. The former was previously shown to carry the $3^{\prime}$ end of hisC, the entire orf 3 and bis $G$ and the $5^{\prime}$ end of bisD (Fig. 2; Delorme et al., 1992), which encode enzymes involved in histidine biosynthesis (HisC, HisG, HisD) and a protein homologous to histidyl tRNA synthetases (Orf3). The same proteins are encoded by the $L$. lactis subsp. cremoris segment, except that frameshift mutations are present in the four genes (at positions 117, 1043, 1945 and 2424). The four gene products are therefore probably inactive, which is expected from the observation that all the $L$. lactis subsp. cremoris strains are auxotrophic for histidine (17 strains tested, Delorme et al., 1993). When corrected for the frameshifts, the potential L. lactis subsp. cremoris gene products share $78,51,83$ and $73 \%$ homology, respectively, with their $L$. lactis subsp. lactis counterparts. Interestingly, codon usage in the better-conserved terminal regions of the $L$. lactis subsp. cremoris sequence is as expected for lactococci, whereas in the highly divergent central region, which encodes $\sim 60 \%$ of Orf3 (the carboxy end) and $\sim 20 \%$ of HisG (the amino end), codon usage is quite atypical (Table 1; only the significantly deviant codons are shown). For instance, codons GTG for valine, GCG for alanine, GAG for glutamine, and CGG and CGC for arginine are preferentially used in this region whereas they occur rarely in other regions of the Lactococcus chromosome (Chopin, 1993). Unusual codon usage, together with the high $\mathrm{G}+\mathrm{C}$ content and the presence of additional DNA (see above) suggest that the central $L$. lactis subsp. cremoris region might originate from a taxonomically distant bacterial species.

\section{Divergence is not due to the loss of function}

Sequence analysis (see above) and phenotype tests (Delorme et al., 1993) show that the his operon of L. lactis subsp. cremoris NCDO 763 is inactive. The question arises whether the divergence might be due to a rapid drift of genes which are no longer used, notwithstanding the atypical codon usage and $\mathrm{G}+\mathrm{C}$ content of the central region. In this case, the corresponding region from different $L$. lactis subsp. cremoris strains might be poorly conserved. To test this possibility a $1.4 \mathrm{~kb}$ segment from two different $L$. lactis subsp. cremoris strains, IL182 and AM2, was amplified by PCR and its sequence determined (Fig. 4). The two coding sequences differ by less than $0.8 \%$ and differ only slightly more, $\sim 3 \%$, from the sequence of the NCDO 763 strain. Moreover, most of the differences between NCDO 763 and the two other strains are either silent (22 and 20 for IL182 and AM2, respectively), or conservative ( 5 and 7 ), as expected for functional diverging genes. In addition, all the changes which affect the protein sequence (10 and 9 for IL182 and AM2, respectively) are present at positions which are not well conserved, suggesting that they do not affect protein function. Finally, the frameshift found in position 1043 of orf 3 from NCDO 763 is not present in the other two strains, which implies that this change occurred relatively recently when the environmental conditions allowed the fixation of this mutation. These results suggest that the region was functional over a long period of time since strain NCDO 763 diverged from IL182 and AM2, and argue against its rapid drift due to the loss of gene function.

It should be noted that the domains of the highly divergent central region which are better conserved than the adjacent domains (see, for instance, the domain close to position 600 , which diverges only $\sim 15 \%$, Fig. 3), code either for the motifs which are typical for class II tRNA synthetases, to which Orf3 belongs (M1 and M2), or for the signature regions (SR1, SR2a and b), specific for histidyl tRNA synthetases (Figs 2 and 3; Raben et al., 1992; Eriani et al., 1990). It is possible that the constraints of preserving protein function might have limited the nucleotide sequence divergence of these domains. 
${ }_{I}^{\text {hisc }}$

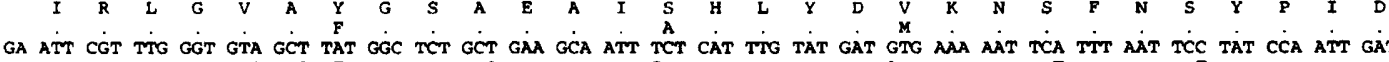
-

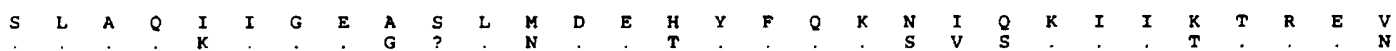
AGT TTG GCA CAA ATT ATT GGA GA GCA AGT TTA ATG GAT GAA CAT TAT TTT CAA AAA AAC ATT CAG AAA ATC ATT AAG ACA AGA GAA GT

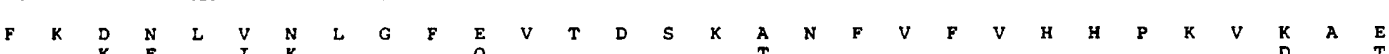
TTT AAA GAT AAT CTG GTT AAT TTA GGA TTT GAA GTG ACT GAT TCA AAG GCT AAC TTT GTT TITT GTT CAT CAT CCA AAA GTA AAA GCA GAA

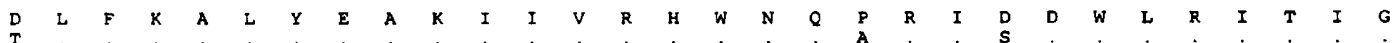

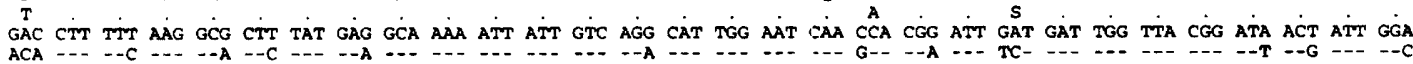

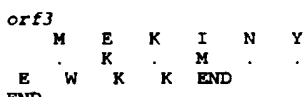

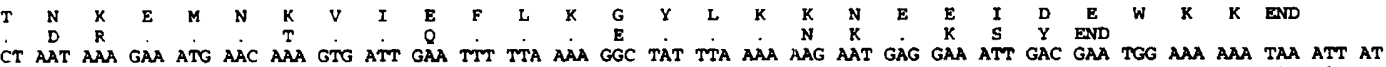
ACT AAT AAA GAA ATG AAC AAA GTG ATT GAA TTT TTA AAA GGC TAT TTA AAA AAG AAT GAG GAA ATT GAC GAA TGG AAA AAA TAA ATT AT

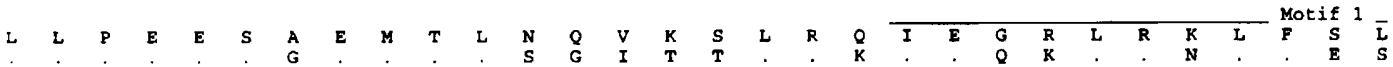

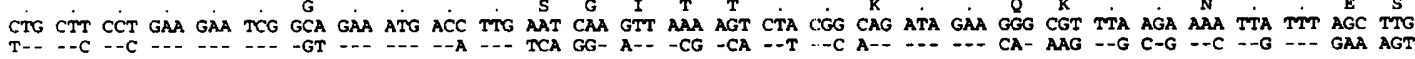

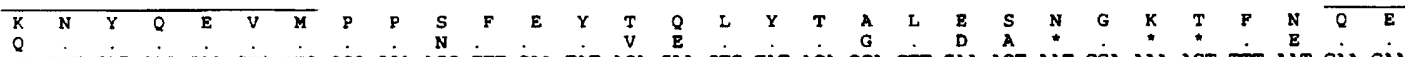
AAA AAT TAT CAG GAA GTC ATG CCC CCA AGC TTT GA TAT ACA CAA CTC TAT ACA GCA CTT GA AGT AAT GGA AAA ACT TTT AAT CAA GAA

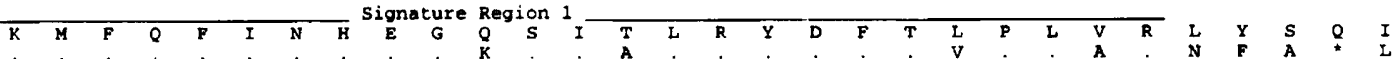
AAA ATG TTT CAG TTT ATC AAT CAT GAG GGA CAA TCA ATT ACA CTT CGT TAT GAT TTT ACA CTT CCT TTA GTT AGA CTC TAT TCG CAA ATC

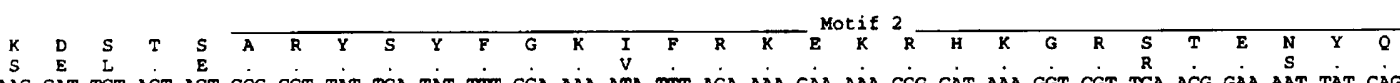
AAG GAT TCT ACT AGT GCC CGT TAT TCA TAT TTT GGA AAA ATA TTT AGA AAA GAA AAA CGG CAT AAA GGT CGT TCA ACG GAA AAT TAT CAंG 808
795

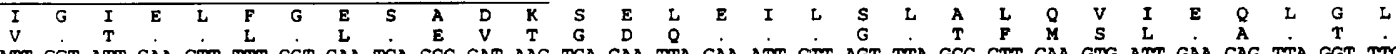

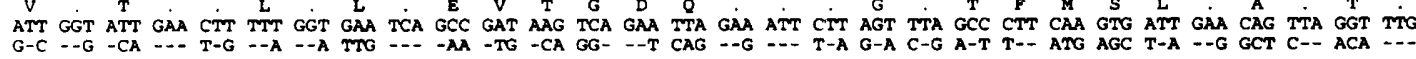

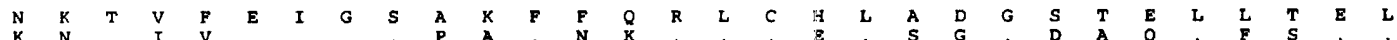
AAT AAA ACG GTC TIT GAA ATA GGC TCA GCA AAA TTT TTT CAA CGT TTA TGT CAT TTA GCT GAC GGT TCA ACA GAG TTA CTT ACA GAA CTT

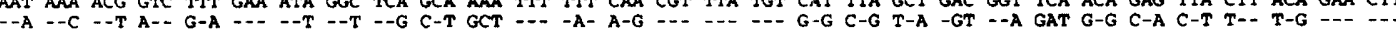

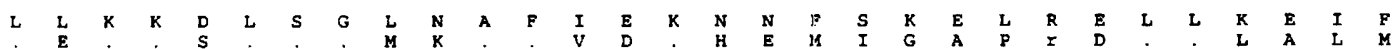
E
TTA CTC AAG AAA GAT TTG AGT GGT CTT C-T GAG --A -.. TCA C-C TCA -.- A-G --A -.. --C G-G --C --G C-- G-A A-G ATA GGC -CG CC- C-* -C T-G -.. CTT -CT T-G A-G 1064

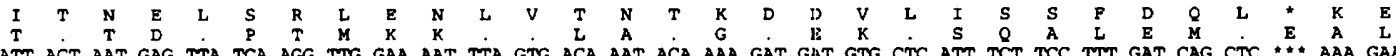
ATT ACT AAT GAG TTA TCA AGG TTS GAA AAT TTA GTG ACA AAT ACA AAA GAT GAT GTG CTC ATT TCT TCC TTT GAT CAG CTC *\# AAA GAA 1165

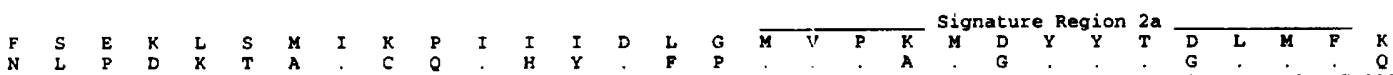
N
TTT TCA GAG AAA CTT TCA ATG ATT AAA CCG ATT ATC ATT GAT TTG GGA ATG GTT CCT AAA ATG GAT TAT TAT ACT GAT TTA ATG TTT AAA 1255
AA- -T- CCT G-C AAG A-- GC-

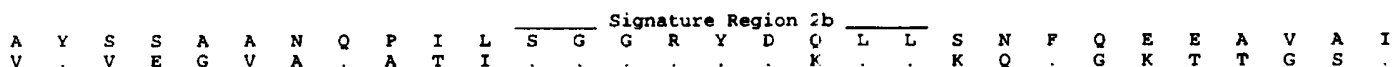
GCT TAC AGT TCA GCA GCG AAT CAA CCT ATT TTA TCA GGT GGA AGA TAT GAC CAA CTA TTA AGT AAT TTT CAA GAA GAG GCG GTT GCC ATT 1345 $\begin{array}{lllllllllllllllllll}G & F & C & C & H & M & D & T & I & L & K & A & L & E & R & Q & E & \ldots & \text { (cont.) }\end{array}$

GGT ITTT TGT TGT CAT ATG GAT ACT ATT TTA AAG GCA CTG GAA AGA CAA GA

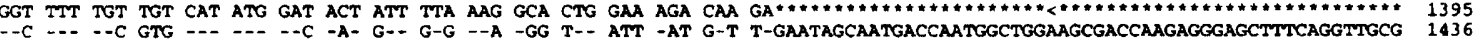
GATAGAAGCTTGCGCAAGCAAGCTGTCAAAGGCGACCAAGGGGAGCTTTCAGGTTGCGGATAGAAGCTTGCGCAAGCAAGCTGTCAAAGGCGACCAAGGGGAGCTTTCAGGTTGCGG 1554

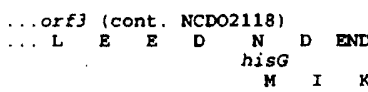

ATAGAAGCTTGCTAGGAAGCTATCTGCTCGCCCTTGGGCAG- TTG GAG GAA GAC A ATG ATT AAA ATT GCC ATA ACT AAA GGT CGA ATC CAA AAA CAA 1451 $\begin{array}{llllllllllllllllllllllllllllll}V & T & K & \text { L } & \text { L } & \text { E } & \text { N } & \text { A } & \text { D } & \mathbf{Y} & \mathbf{D} & \mathrm{V} & \mathbf{E} & \mathbf{P} & \mathbf{I} & \mathbf{L} & \mathbf{N} & \mathbf{L} & \mathbf{G} & \mathbf{R} & \mathbf{E} & \mathbf{L} & \mathbf{Q} & \mathbf{I} & \mathbf{K} & \mathbf{T} & \mathbf{K} & \mathbf{D} & \mathbf{D} & \mathbf{L}\end{array}$

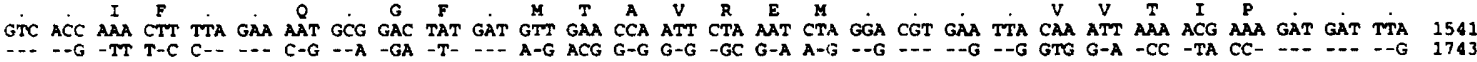

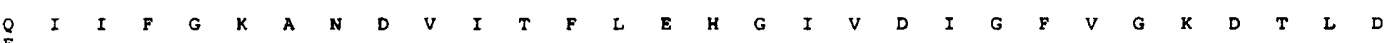
CAA ATC ATT TTT GGA AAA GCT AAT GAT GTC ATT ACT TTT TTA GAA CAT GGA ATT GTT GAT ATT GGC TTT GTT GGT AAA GAT ACG CTT GAT 1631

Fig. 2. For legend see facing page. 
$\begin{array}{llllllllllllllllllllllllllllllllll}E & N & D & F & D & D & Y & Y & E & L & L & D & L & K & I & G & Q & C & I & F & A & L & A & S & Y & P & D & F & S & N\end{array}$

GAA AAT GAT TTT GAT GAT TAT TAT GAA TTA TTG GAT TTA AAA ATT GGG CAG TGT ATT TTT GCC CTT GCT TCC TAT CCCT GAC TTT TCA AAT 1721

$\begin{array}{lllllllllllllllllllllllllllllllll}K & N & F & Q & R & R & K & R & I & A & S & K & Y & P & R & V & T & K & K & Y & F & A & Q & K & Q & E & D & I & E & I\end{array}$

$K$
AAA AAT TTT CAA AGA CGT AAA CEA ATT GCT TCA AAA TAT CCA AGA GTG ACA AAA ANA TAT TTT GCT CAA AAG CAA GAA GAT ATT GAA ATT 1811

$\begin{array}{llllllllllllllllllllllllllllllllll}I & K & L & E & G & S & V & E & L & G & P & V & V & G & L & A & D & A & I & V & D & I & V & E & T & G & N & T & L & S\end{array}$

ATC AAG TTG GAA GGT TCT GTT GAG CTT GGA CCA GTT GTT GGT TTA GCT GAT GCA ATT GTT GAC ATT GTC GAA CAA GGA AAT ACT TTA TCT 1901

$\begin{array}{lllllllllllllllllllllllllllllllll}A & N & G & L & E & V & I & E & K & I & S & D & I & S & T & R & M & I & V & N & K & S & S & F & K & F & K & K & D & K\end{array}$

GCA AAT GGT TTSA GAG GTC ATT GAA AAA ATC AGT GAC ATT TCA ACA CGG ATG ATT GTC AAT AAA TCT AGT TTC AAA TITT AAA AAA GAT AAA 1991

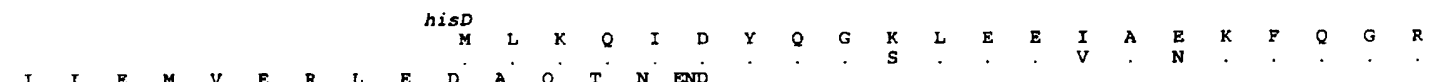

I I

ATT ATA GAA ATG GTG GAG AGG TTA GAA GAT GCT CAंA ACA AAT TGAT TAT CAA GGA AAG CTT GAA GAA ATT GCT GAA AAA TTT CAA GGT CGA 2082

$\begin{array}{llllll} & \end{array}$

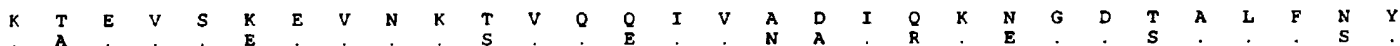

MAM ACA GAA GTA TCA AAA GAA GTT AAT AAA ACT GTT CAA CAG ATT GTA GCA GAC ATT CAA AAA AAT GGA GAT ACT GCC TTA TTT AAC TAT 2172

$\begin{array}{llllllllllllllllllllllllllllllllll}\mathbf{A} & \mathbf{K} & \mathbf{K} & \mathbf{F} & \mathbf{D} & \mathbf{G} & \mathbf{Y} & \mathbf{D} & \mathbf{V} & \mathbf{N} & \mathbf{T} & \mathbf{S} & \mathbf{N} & \mathbf{L} & \mathbf{L} & \mathbf{V} & \mathbf{T} & \mathbf{R} & \mathbf{M} & \mathbf{E} & \mathbf{R} & \mathbf{E} & \mathbf{A} & \mathbf{G} & \mathbf{L} & \mathbf{E} & \mathbf{O} & \mathbf{I} & \mathbf{D} & \mathbf{E} \\ \end{array}$

GCC AAA AAG TTC GAC GGT TAT GAT GTG AAT ACT AGT AAT TTA CTG GTC ACG CGC ATG GAA CGT GAA GCA GGA CTA GAA CAA ATT GAT GAG 2262

$\begin{array}{llllll}D & Y & F & R & I\end{array}$

GAT TAT TTT AGA ATT C
A--
- C

Fig. 2. Comparison of the nucleotide sequences and the putative translation products from $L$. lactis subsp. lactis NCDO 2118 (first and third lines) and L. lactis subsp. cremoris NCDO 763 (second and fourth lines). Conserved motifs 1 and 2 of class II tRNA synthetases, and signature regions 1 and 2 of histidyl tRNA synthetases (Eriani et al., 1990; Raben et al., 1992) are indicated. Stars indicate the missing nucleotides or amino acids. The translation products are shown irrespective of the frameshifts, to allow comparison over their entire length.

\section{DISCUSSION}

The level of divergence between $L$. lactis subsp. lactis and $L$. lactis subsp. cremoris varies considerably along a large region of the chromosome. It is low $(10-20 \%)$ in conserved regions, which agrees with comparisons of the 16S rRNA sequences (Salama et al., 1991) and with global DNA-DNA homology measurements (Jarvis et al., 1981), but is very high $(35-65 \%)$ in variable regions. The conserved and variable regions are interspersed, which suggests that the chromosomal region studied has a mosaic structure.

The divergence appears not to be due to an abnormally rapid genetic drift, as indicated by analysis of a region of the his operon which is highly divergent between L. lactis subsp. lactis and cremoris, but is remarkably well conserved among different $L$. lactis subsp. cremoris strains. Several features of this region in $L$. lactis subsp. cremoris are not representative of the genus Lactococcus, such as a high $\mathrm{G}+\mathrm{C}$ content, unusual codon bias and the presence of a repeated DNA element, suggesting that it might have been acquired by horizontal gene transfer from distantly related bacteria. This interpretation is supported by the existence of a rather sharp boundary between this atypical region and the adjacent lactococcus-like $3^{\prime}$ region. Genes acquired by horizontal transfer often have unusual $\mathrm{G}+\mathrm{C}$ content and codon bias, as shown by extensive analysis of E. coli sequences (Médigue et al., 1991). Comparable results have also been found in other bacterial genera
(Groisman et al., 1992; Shanley et al., 1994). It is not known at present from which species the divergent $L$. lactis subsp. cremoris region was derived.

The postulated horizontal gene transfer is certainly not restricted to the bis operon, since interspersion of conserved and divergent regions was also detected in the $\mathrm{BCAA}$ and the trp operons. The sequence of these regions of the L. lactis subsp. lactis chromosome is known (Delorme $e t$ al., 1992) and its analysis did not reveal any distortion in the $\mathrm{G}+\mathrm{C}$ content or codon bias from other lactococcal genes. Our results do not permit the conclusion that all $L$. lactis subsp. cremoris divergent regions deviate from the lactococcal model (as does the divergent his region) but point to the mosaic structure of the L. lactis subsp. cremoris chromosome. The genes analysed here are grouped in two regions. The bis and the BCAA operons are adjacent and $\sim 200 \mathrm{~kb}$ from the trp operon (Tulloch et al., 1991; Le Bourgeois et al., 1992). Future work should establish whether the L. lactis subsp. cremoris chromosome is mosaic only in these two regions or whether the mosaicism extends further along.

DNA acquired by heterospecific gene transfer may be associated with extrachromosomal elements. For instance, sequences showing a high similarity with the incFII-oriT region of plasmid R 100 and with a region of the $145 \mathrm{~kb}$ plasmid harbouring the gene for the heat-stable toxin (est $A I$ ) were found in an E. coli strain 350 and $400 \mathrm{bp}$ upstream of the $p h o N$ and $\sin \mathrm{R}$ loci, respectively (Groisman $e$ t al., 1992, 1993). Similarly, the bin and est AI 


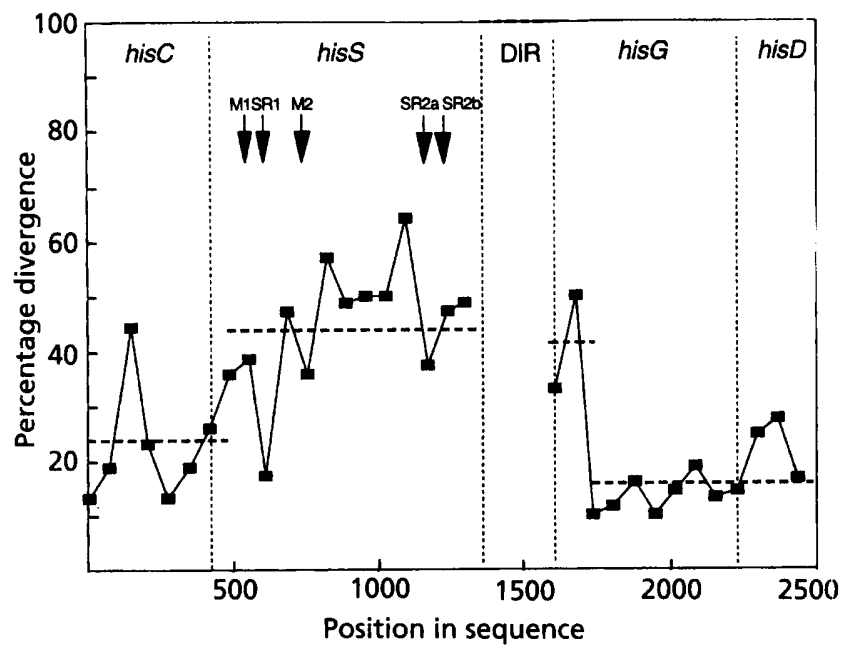

Fig. 3. Divergence between the L. lactis subsp. lactis NCDO 2118 and $L$. lactis subsp. cremoris NCDO 763 sequences. The squares connected by the solid line represent the mean divergence over a $70 \mathrm{bp}$ sequence and the horizontal dashed line represents the mean of the region covered. Nucleotide positions in the $L$. lactis subsp. cremoris NCDO 763 sequence are indicated on the abscissa. $M$ and SR denote conserved motifs and signature regions present in orf3 (indicated in Fig. 2) and the arrows show their position. The ORFs indicated at the top are delimited by vertical dashed lines; DIR, direct repeat. regions are associated with a transposon-like element (Simon et al., 1980) or an insertion sequence (Groisman et al., 1993). Interestingly, a conjugative element has been mapped at a position less than $50 \mathrm{~kb}$ away from the bis operon carrying the mosaic genes in $L$. lactis subsp. cremoris chromosome (P. Le Bourgeois, personal communication). Furthermore, the L. lactis subsp. cremoris bis region contains an element that is reminiscent of prokaryotic repetitive DNA sequences such as REP and ERIC (Higgins et al., 1988; Hulton et al., 1991; Gilson et al., 1991). It is therefore possible that the mosaicism is restricted to only a portion of the $L$. lactis subsp. cremoris chromosome, which would permit reconciliation of the reported overall DNA homology (Jarvis et al., 1981) with the high local divergence observed in the present work.

Interestingly, the operons resulting from the postulated gene transfer may all have been functional. The trp operon is known to be active (Reiter \& Oram, 1962) and the his operon was presumably active, as deduced from the conservative base change pattern among different $L$. lactis subsp. cremoris strains. It has been reported that intraspecific gene exchange may generate functional genes, such as those involved in penicillin resistance of Neisseria (Spratt et al., 1992; Maynard Smith et al., 1991) or Streptococcus (Martin et al., 1992; Dowson et al., 1989). However, the exchange that occurred in these cases, as well as the extensive recombination in the $r f b$ O-antigen locus in Salmonella enterica (Reeves, 1993) were generated under intense selection. Our results represent the first indication that a hetero-specific gene exchange might

Table 1. Codon usage in lactococci

\begin{tabular}{|c|c|c|c|c|c|}
\hline \multirow[t]{2}{*}{ Codon* } & \multicolumn{2}{|c|}{ Total codon number } & \multicolumn{3}{|c|}{ Codon proportion (\%) } \\
\hline & $\begin{array}{l}\text { Central } \\
\text { region } \dagger\end{array}$ & $\begin{array}{l}\text { Terminal } \\
\text { regions } \ddagger\end{array}$ & $\begin{array}{l}\text { Central } \\
\text { region }\end{array}$ & $\begin{array}{l}\text { Terminal } \\
\text { regions } \neq\end{array}$ & $\begin{array}{c}\text { Total } \\
\text { lactococci } \S\end{array}$ \\
\hline TTA (Leu) & 8 & 15 & 19 & 44 & 31 \\
\hline TTG (Leu) & 14 & 8 & 34 & 23 & 23 \\
\hline GT'T (Val) & 3 & 11 & 14 & 52 & 48 \\
\hline GTG (Val) & 8 & 4 & 38 & 19 & 13 \\
\hline GCT (Ala) & 4 & 9 & 17 & 37 & 39 \\
\hline GCG (Ala) & 8 & 1 & 43 & 4 & 11 \\
\hline CAA (Gln) & 6 & 13 & 37 & 93 & 82 \\
\hline CAG (Gln) & 10 & 1 & 63 & 7 & 18 \\
\hline AAA (Lys) & 13 & 33 & 54 & 77 & 77 \\
\hline AAG (Lys) & 11 & 10 & 46 & 23 & 23 \\
\hline GAA (Glu) & 16 & 28 & 57 & 76 & 83 \\
\hline GAG (Glu) & 12 & 9 & 43 & 24 & 17 \\
\hline CGG (Arg) & 3 & 5 & 19 & 6 & 6 \\
\hline CGC (Arg) & 5 & 1 & 31 & 12 & 9 \\
\hline AGA (Arg) & 1 & 5 & 6 & 29 & 29 \\
\hline
\end{tabular}

* Only the codons showing significant differences between central and terminal regions are shown.

† Positions 481-1356 and 1600-1740 from L. lactis subsp. lactis NCDO 763.

$\ddagger$ Positions $1-480$ and 1741-2478 from L. lactis subsp. lactis NCDO 763 .

§From Chopin (1993). 
orf 3 T : : G ACG ATT GGC ACT GAT AGA GAS ATG AAC ACA GTG ATT CAA TTC TTA AAG GAA TAT TTA AAA AAC AAG GAG AAA AGT TAC TG A TG AAA AAA ATG AAC TAT TTG CTC CCC GAA GAA TCG GGT

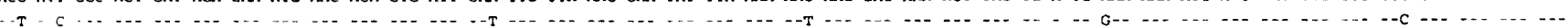

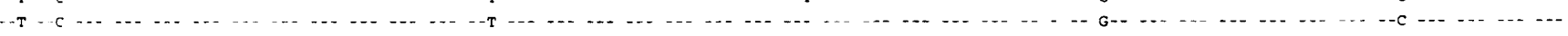

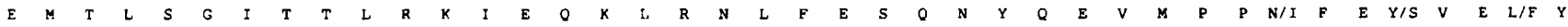
GAA ATG ACA TTG TCA GGA ATT ACG ACA CTT CGC AAG ATA GAA CAG AAG TTG CGG AAC TTG TTT GAA AGT CAA AAT TAT CAG GAG GTC ATG CCA CCG AAT TTT GAA TAT GTC GAG CTT TAT C... 1.2
2

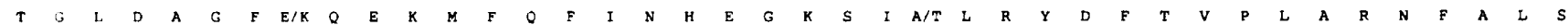
ACT GGC CTT GAC GCA GGA TTT GAG CAA GAG AAG ATG TTT CAA TTT ATC AAT CAT GAG GGT AAA TCG ATT GCC CTT CGT TAT GAT TTT ACA GTC CCT TTG GCA CGA AAT TTT GCC TTA TCA $\because A$ -

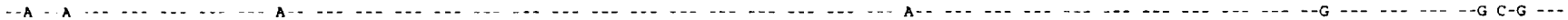
E L L T/K E GAG CTG ACA GAA GCC CGG TAT AGT TAT TTT GGT AAG GTG TTT CGT AAA GAA AAG CGT CAT AAG GGA CGT CGG ACG GAG AGC TAT CAG GTC GGG ACA GAA TTG TTA GGA TTG TCA GAA GTG -.

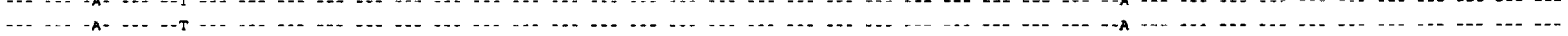

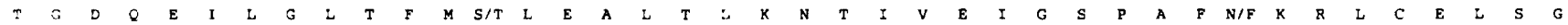
ACA GGA GAT CAG GAG ATT TTA GGA CTG ACT TTT ATG AGC TTA GAG GCT CTA ACA TTG AAA AAC ACT ATC GTA GAA ATT GGT TCG CCT GCT TTT TAT AAG CGT TTA TGT GAG CTG TCA GGT $\begin{array}{llll}\cdots & \end{array}$

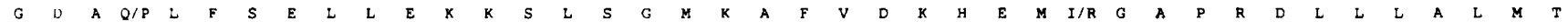
GGA GAT GCG CAA CTT TTT TCG GAA CTT CTT GAG AAA AAA TCA CTC TCA GGT ATC AAA GCT TTC GTG GAC AaG CAT GAA ATG ATA GGC GCG CCA CG* GAC TTG TTG CTT GCT TTG ATG ACC

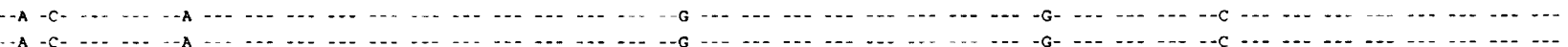

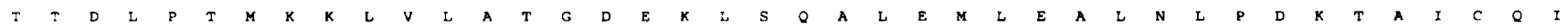
ACG ACC GAT TTG CCA ACC ATG AAA AAA TTA GTT TTG GCA ACA GGC GAT GAA AAA TTG TCT CAG GCA CTC GAA ATG CTT GAA GCG CTG AAT TTA CCT GAC Aag ACA GCG ATT TGC CAG ATT ...

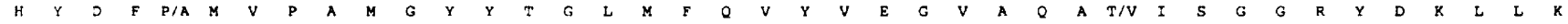
CAC TAT GAT TTT CCC ATG GTA CCT GCC ATG GGC TAC TAT ACT GGG CTG ATG TTT CAG GTT TAC GTA GAA GGC GTG GCG CAA GCG ACT ATA TCC GGT GGG CGC TAT GAC AAG TTA CTA AAA $\begin{array}{llll}1 & \end{array}$

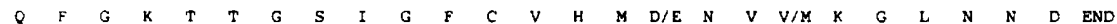

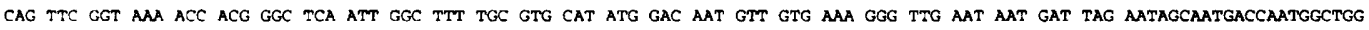

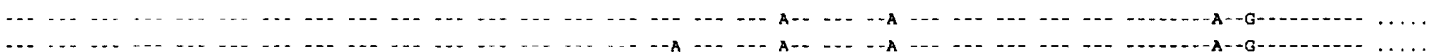

DIR SEQUENCES

hisG

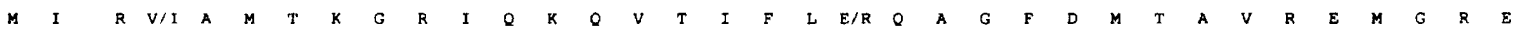

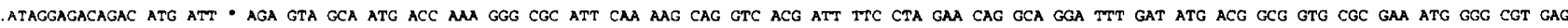
$\ldots$
$\ldots$ L $\quad \begin{array}{llllllllllllllllllllllllll} & V & V & T & I & P & D & D & L & E & I & I & F & G & K & A & N & D & V & I & T & F & L & E\end{array}$ TTG GTG GTA ACC ATA CCA GAT GAT TTC GAA ATT ATT TTS GGA AAA GCC AAT GAT GTC ATA ACT TTT TTG GAG

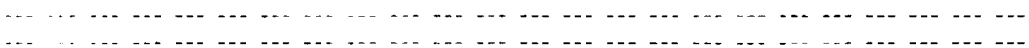

Fig. 4. Sequence comparisons within the his region of $L$. lactis subsp. cremoris strains NCDO 763, IL182 and AM2. The NCDO 763 DNA sequence is shown in the second line; IL182 and AM2 sequences are represented in the third and the fourth lines, respectively. Dashes indicate the same nucleotides as in the NCDO 763 sequence. NCDO 763 amino acid sequence is indicated in the first line. Amino acids which vary in IL182 or AM2 are indicated, separated by a slash, after the corresponding amino acid from NCDO 763.

yield functional biosynthetic pathway genes, and this presumably not under selective pressure since bacterial phenotype should not be affected.

\section{ACKNOWLEDGEMENTS}

We thank A. Khodja for technical assistance, J. Bardowski for providing trp probes and C. Anagnostopoulos for critical reading of the manuscript. This work was supported in part by
BRIDGE contract BIOTCT91-0263 of the Commission of the European Communities.

\section{REFERENCES}

Bardowski, J., Ehrlich, S. D. \& Chopin, A. (1992). Tryptophan biosynthesis genes in Lactococcus lactis subsp. lactis. J Bacteriol 174, 6563-6570.

Chopin, A. (1993). Organization and regulation of genes for amino 
acid biosynthesis in lactic acid bacteria. FEMS Microbiol Rev 12 21-38.

Collins، M. D., Ash, C., Farrow, J. A. E., Wallbanks, S. \& Williams, A. M. (1989). $16 \mathrm{~S}$ ribosomal ribonucleic acid sequence analyses of lactococci and related taxa. Description of Vagococcus fluvialis gen. nov., sp. nov. J Appl Bacteriol 67, 453-460.

Delorme, C., Ehrlich, S. D. \& Renault, P. (1992). Histidine biosynthesis genes in Lactococcus lactis subsp. lactis. J Bacteriol 174 6571--6579.

Delorme, C., Ehrlich, S. D. \& Renault, P. (1993). Gene inactivation in Lactococcus lactis. II. Histidine biosynthesis. I Bacteriol 175, 4391-4399.

Dowson, C. G., Hutchison, A., Brannigan, J. A., George, R. C., Hansman, D., Lineares, J., Tomasz, A., Maynard Smith, J. M. \& Spratt, B. G. (1989). Horizontal transfer of penicillin-binding protein genes in penicillin-resistant clinical isolates of Streptococcus pneumoniae. Proc Natl Acad Sci USA 86, 8842-8846.

Eriani, G., Delarue, M., Poch, O., Gangioff, J. \& Moras, D. (1990). Partition of $\mathrm{tRNA}$ synthetases into two classes based on mutually exclusive sets of sequence motifs. Nature 347, 203-206.

Fox, G. E., Wisotzkey, J. D. \& Jurtshuk, P., Jr (1992). How close is close: $16 \mathrm{~S}$ rRNA sequence identity may not be sufficient to guarantee species identity. Int J Syst Bacteriol 42, 166-170.

Garvie, E. I. \& Farrow, J.A.E. (1982). Streptococcus lactis subsp. cremoris (Orla-Jensen) comb. nov. and Streptococcus lactis subsp. diacetylactis (Matuszewski et al.) nom. rev., comb. nov. Int J Syst Bacteriol 32, 453-455.

Gilson, E., Saurin, W., Perrin, D., Bachellier, S. \& Hofnung, M. (1991). The BIME family of bacterial highly repetitive sequences. Res Microbiol 142, 217-222.

Godon, J. J., Chopin, M.-C. \& Ehrlich, S. D. (1992a). Branched chain amino acid biosynthesis genes in Lactococcus lactis subsp. lactis. J Bacteriol 174, 6580-6589.

Godon, J. J., Delorme, C., Ehrlich, S. D. \& Renault, P. (1992b). Divergence of genomic sequences between Lactococcus lactis subsp. lactis and Lactococcus lactis subsp. cremoris. Appl Environ Microbiol 58, 4045-4047.

Groisman, E. A., Saier, M. H., Jr \& Ochman, H. (1992). Horizontal transfer of a phosphatase gene as evidence for mosaic structure of the Salmonella genome. EMBO J 11, 1309-1316.

Groisman, E. A., Sturmoski, M. A., Solomon, F. R., Lin, R. \& Ochman, H. (1993). Molecular, functional and evolutionary analysis of sequences specific to Salmonella. Proc Natl Acad Sci US A 90, $1033-1037$.

Higgins, C. F., McLaren, R. S. \& Newbury, S. F. (1988). Repetitive extragenic palindromic sequences, mRNA stability and gene expression: evolution by gene conversion? - a review. Gene $\mathbf{7 2}$, $3-14$.

Hulton, C. S. J., Higgins, C. F. \& Sharp, P. M. (1991). ERIC sequences: a novel family of repetitive elements in the genomes of Escherichia coli, Salmonella typhimurium and other enterobacteria. Mol Microbiol 5, 825-834.

Jarvis, A. W. \& Jarvis, B. D.W. (1981). Deoxyribonucleic acid homology among lactic streptococci. Appl Environ Microbiol 41, $77-83$.

Le Bourgeois, P., Lautier, M., Mata, M. \& Ritzenthaler, P. (1992). Physical and genetic map of the chromosome of Lactococcus lactis subsp. lactis IL1403. J Bacteriol 174, 6752-6762.

Loureiro Dos Santos, A. L. \& Chopin, A. (1987). Shotgun cloning in Streptococcus lactis. FEMS Microbiol Lett 42, 209-212.

Martin, C., Sibold, C. \& Hakenbeck, R. (1992). Relatedness of penicillin-binding protein 1a genes from different clones of penicillin-resistant Streptococcus pneumoniae isolated in South Africa and Spain. EMBO J 11, 3831-3836.

Maynard Smith, J., Dowson, C. G. \& Spratt, B. G. (1991). Localized sex in bacteria. Nature 349, 29-31.

Médigue, C., Rouxel, T., Vigier, P., Hénaut, A. \& Danchin, A. (1991). Evidence for horizontal gene transfer in Escherichia coli speciation. J Mol Evol 222, 851-856.

Raben, N., Borriello, F., Amin, J., Horwitz, R., Fraser, D. \& Plotz, P. (1992). Human histidyl-tRNA synthetase: recognition of amino acid signature regions in class $2 \mathrm{a}$ aminoacyl-tRNA synthetases. Nucleic Acids Res 20, 1075-1081.

Reeves, P. (1993). Evolution of Salmonella $\mathrm{O}$ antigen variation by interspecific gene transfer on a large scale. Trends Genet 9, 17-22.

Reiter, B. \& Oram, J. D. (1962). Nutritional studies on cheese starters. J Dairy Res 29, 63-77.

Salama, M., Sandine, W. \& Giovannoni, S. (1991). Development and application of oligonucleotide probes for identification of Lactococcus lactis subsp cremoris. Appl Environ Microbiol 57, $1313-1318$

Sambrook, J., Fritsch, E. F. \& Maniatis, T. (1989). Molecular Cloning: a Laboratory Manual, 2nd edn. Cold Spring Harbor, NY: Cold Spring Harbor Laboratory.

Shanley, M. S., Harrisson, A., Parales, R. E., Kowalchuck, G., Mitchell, D. \& Ornston, L. N. (1994). Unusual G + C content and codon usage in catIJF, a segment of the ben-cat supra-operonic cluster in the Acinetobacter calcoaceticus chromosome. Gene 138, $59-65$.

Simon, M., Zieg, J., Silverman, M., Mandel, G. \& Doolittle, R. (1980). Phase variation: evolution of a controlling element. Science 209, 1370-1374.

Spratt, B. G., Bowler, L. D., Zhang, J. \& Maynard Smith, J. (1992). Role of interspecies transfer of chromosomal genes in the evolution of penicillin resistance in pathogenic and commensal Neisseria species. J Mol Evol 34, 115-125.

Terzaghi, B. \& Sandine, W. E. (1975). Improved medium for lactic streptococci and their bacteriophages. Appl Microbiol 29, 807-813.

Tulloch, D. L., Finch, L. R., Hillier, A. J. \& Davidson, B. E. (1991). Physical map of the chromosome of Lactococcus lactis subsp. lactis DL11 and localization of six putative rRNA operons. $J$ Bacteriol 173, 2768-2775.

Vieira, J. \& Messing, J. (1987). Production of single-stranded plasmid DNA. Methods Enzymol 153, 3-11.

Received 11 April 1994; revised 30 June 1994; accepted 12 July 1994. 